\title{
Axillary Dissection Versus No Axillary Dissection in Elderly Patients with Breast Cancer and No Palpable Axillary Nodes: Results After 15 Years of Follow-Up
}

\author{
Gabriele Martelli, $\mathrm{MD}^{1}$, Rosalba Miceli, $\mathrm{PhD}^{2}$, Maria Grazia Daidone, $\mathrm{PhD}^{3}$, Gaetano Vetrella, $\mathrm{MD}^{4}$, \\ Anna Maria Cerrotta, $\mathbf{M D}^{\mathbf{5}}$, Domenico Piromalli, $\mathrm{MD}^{\mathbf{1}}$, and Roberto Agresti, $\mathrm{MD}^{\mathbf{1}}$ \\ ${ }^{1}$ Breast Unit, Fondazione IRCCS Istituto Nazionale dei Tumori, Milan, Italy; ${ }^{2}$ Unit of Clinical Epidemiology and Trial \\ Organization, Fondazione IRCCS Istituto Nazionale dei Tumori, Milan, Italy; ${ }^{3}$ Unit of Biomolecular Determinants in \\ Prognosis and Therapy, Fondazione IRCCS Istituto Nazionale dei Tumori, Milan, Italy; ${ }^{4}$ Unit of Preventive Gynecology, \\ Melegnano Hospital, Melegnano, Italy; ${ }^{5}$ Unit of Radiotherapy, Fondazione IRCCS Istituto Nazionale dei Tumori, Milan, \\ Italy
}

\begin{abstract}
Objective. To assess the long-term safety of no axillary clearance in elderly patients with breast cancer and nonpalpable axillary nodes.

Background. Lymph node evaluation in elderly patients with early breast cancer and clinically negative axillary nodes is controversial. Our randomized trial with 5-year follow-up showed no breast cancer mortality advantage for axillary clearance compared with observation in older patients with T1N0 disease.

Methods. We further investigated axillary treatment in a retrospective analysis of 671 consecutive patients, aged $\geq 70$ years, with operable breast cancer and a clinically clear axilla, treated between 1987 and 1992; 172 received and 499 did not receive axillary dissection; $20 \mathrm{mg} / \mathrm{day}$ tamoxifen was prescribed for at least 2 years. We used multivariable analysis to take account of the lack of randomization.
\end{abstract}

Results. After median follow-up of 15 years (interquartile range 14-17 years) there was no significant difference in breast cancer mortality between the axillary and no axillary clearance groups. Crude cumulative 15-year incidence of axillary disease in the no axillary dissection group was low: $5.8 \%$ overall and $3.7 \%$ for $\mathrm{pT} 1$ patients.

(C) The Author(s) 2010. This article is published with open access at Springerlink.com

First Received: 19 March 2010;

Published Online: 23 July 2010

G. Martelli, MD

e-mail: gabriele.martelli@istitutotumori.mi.it
Conclusions. Elderly patients with early breast cancer and clinically negative nodes did not benefit in terms of breast cancer mortality from immediate axillary dissection in this nonrandomized study. Sentinel node biopsy could also be foregone due to the very low cumulative incidence of axillary disease in this age group. Axillary dissection should be restricted to the small number of patients who later develop overt axillary disease.

In Western countries, nearly a third of breast cancers occur in patients over 65 years of age. ${ }^{1}$ The probability of developing the disease increases with age, and greatest incidence is in women aged 75-79 years. ${ }^{2}$ The gold-standard treatment for elderly patients with breast cancer is surgery. Randomized clinical trials that compared tamoxifen as sole initial treatment with surgery in elderly patients with operable breast cancer showed no significant difference between the arms in terms of survival, but unacceptably high local relapse rates in the tamoxifen group: most of these patients required surgery to control local disease progression. ${ }^{3-6}$ Given the central role of surgery as primary therapy, the question arises as to whether surgical evaluation of the axilla can be safely omitted in elderly patients with primary breast cancer and clinically negative axillary nodes.

Axillary dissection is no longer a routine part of the surgical treatment of breast cancer, having been replaced by the less invasive sentinel node biopsy in women with a clinically negative axilla. ${ }^{7-10}$ In fact, axillary surgery is now considered mainly a staging procedure that does not seem to influence breast cancer mortality, since the risk of 
developing metastasis depends mainly on the biological behavior of the primary. ${ }^{11}$ Axillary surgery seems even less important in elderly women because of their high mortality from competing events and the ability of hormone therapy to achieve long-term disease control. ${ }^{12,13}$

Five-year results of our randomized trial comparing primary surgery with and without axillary clearance in T1N0 breast cancer patients $\geq 65$ years of age showed that axillary surgery may be safely omitted without affecting breast cancer mortality or overall survival. ${ }^{14}$ The outcome of this trial fully supported the results of our previous retrospective analysis of consecutive prospectively recruited elderly patients with early breast cancer who also received conservative surgery with or without axillary dissection: After median follow-up of 75 months there was no difference in breast cancer mortality between the two groups. ${ }^{15}$ In this paper we present 15-year follow-up results from the same nonrandomized cohort.

\section{PATIENTS AND METHODS}

\section{Patients and Treatment}

Between January 1987 and December 1992, 1,451 consecutive patients aged $\geq 70$ years presented at the Istituto Nazionale Tumori, Milan, with primary breast cancer. The present study is concerned with the 671 patients of our previous study with operable invasive breast cancer and no palpable axillary nodes who underwent conservative surgery with (172 patients) or without axillary dissection (499 patients). ${ }^{15}$ Patients with synchronous bilateral breast carcinoma, distant metastasis at diagnosis or previous cancer at another site were excluded, as were patients with involved resection margins, since they were candidates for re-excision or radiotherapy.

Postoperative radiotherapy to the breast (not the axilla) was administered to 229 patients and started within 4 weeks of surgery. A cobalt unit or a 6-MeV linear accelerator was used to deliver a total of $50 \mathrm{~Gy}$ (daily target dose of $2 \mathrm{~Gy}$ ) to the residual breast parenchyma in two opposing tangential fields over 5 weeks. A 10 Gy boost was given to the tumor bed. Whether or not axillary dissection and radiotherapy were given depended on patient preference and the opinion of the treating physician. Regardless of hormone receptor status all patients were prescribed $20 \mathrm{mg}$ /day tamoxifen after surgery for at least 2 years.

\section{Hormone Receptor Determination}

Tumor specimens were assayed for estrogen receptor (ER) and progesterone receptor (PgR) levels using the dextran-coated charcoal technique according to Ronchi et al. ${ }^{16}$ Receptors levels were expressed in fmol $\mathrm{mg}^{-1}$ cytosol protein. Tumors with ER concentration $\leq 10 \mathrm{fmol}$ cytosol protein were considered ER negative (ER-); those with PgR concentration $\leq 25$ fmol cytosol protein were considered $\mathrm{PgR}$ negative $(\mathrm{PgR}-)$. Tumors with receptor content above these values were considered receptor positive $(\mathrm{ER}+, \mathrm{PgR}+)$.

\section{Follow-Up}

Patients were seen every 6 months at the outpatient department of our institute for the first 5 years, and yearly thereafter. Mammography and chest X-ray were performed annually, and bone scan every 2 years. Disease status or cause of death was ascertained from clinical records or by contacting patients' general practitioners for patients no longer in follow-up.

Median follow-up was 180 months (interquartile range 168-199 months) in the group without axillary dissection, and 196 months (174-216 months) in the group with axillary dissection.

\section{Statistical Analysis}

The main endpoint for investigating the prognostic effect of axillary dissection was breast cancer death. Additional endpoints were: axillary relapse (in patients not receiving axillary dissection), distant metastasis, and ipsilateral breast tumor recurrence (IBTR). Date of surgery was taken as time zero for all analyses; in the absence of any event, time was censored at the hypothetical study closing date of June 30, 2006. Analyses were performed in a competing-risk framework: when analyzing breast cancer mortality, competing events were death from other malignancy or from other causes; when analyzing each of the breast cancer events (axillary relapse, distant metastasis, IBTR), competing events were the other two possible events, as well as contralateral cancer, other malignancy, and death without evidence of breast disease. ${ }^{17}$

For descriptive purposes we estimated the crude (unadjusted) cumulative incidences of axillary relapse, distant metastasis, and breast cancer death for different axillary treatment and treatment-covariate subsets. ${ }^{17}$ Cumulative incidence curves were compared using the Gray test. ${ }^{18}$

The main analysis, to examine the prognostic effect of axillary dissection, was performed in a multivariable setting, because the study was not randomized and treatment effect estimation had to take into account imbalances between the groups for baseline and prognostic characteristics. Cox models were used to investigate effect of treatment (axillary dissection versus no axillary dissection) on distant metastasis and breast cancer death, by estimating 
treatment hazard ratios with corresponding $95 \%$ confidence intervals. The models included prognostic factors (postoperative breast radiotherapy, pathological tumor size, histologic type, receptor status) modeled using dummy variables, and also propensity score as a linear term to adjust for imbalances in baseline variables influencing the decision to perform axillary dissection. ${ }^{15,19}$

We also used a multivariable Fine and Gray model to perform a statistical comparison of cumulative incidence of breast cancer mortality in the groups that received and did not receive axillary dissection, adjusting for baseline and prognostic characteristics. ${ }^{20}$ We then ran another model that included the axillary dissection $\times \mathrm{pT}$ interaction term to test the heterogeneity of adjusted cumulative incidence of breast cancer mortality in the groups that received and did not receive axillary dissection, according to pT categories.

Similar Fine and Gray models (including axillary dissection, covariates, radiotherapy propensity score, and in another model, the radiotherapy $\times \mathrm{pT}$ interaction) were used for statistical comparison of cumulative IBTR incidence in the groups that received and did not receive residual breast radiotherapy, according to $\mathrm{pT}$ categories.

In both the Cox and Fine and Gray models the prognostic factors were tested by two-sided Wald tests. $p$-Values $<0.05$ were considered significant. The SAS statistical package and $\mathrm{R}$ software were used to carry out the analyses. ${ }^{21,22}$

TABLE 1 Characteristics of 671 elderly patients with operable breast cancer and no palpable axillary nodes who underwent conservative surgery, divided into axillary dissection and no axillary dissection groups

$I Q R$ interquartile range

a Percentages on 641 available values

\section{RESULTS}

Clinical characteristics by axillary treatment group for the entire series are presented in Table 1. Age distribution was similar in the two groups. Radiotherapy was performed more often in the axillary dissection group (chi-square $p<0.001$ ). Most patients had pT1 disease, with greater frequency in the axillary dissection group (chi-square $p<0.001)$. Infiltrating ductal carcinoma was the predominant histologic type; the axillary dissection group had a higher percentage of both ductal and lobular carcinomas (chi-square $p=0.008$ ).

Concentrations of ER and PgR receptors were determined in 641 patients, 617 of whom (91.6\%) were receptor positive (ER+, PgR+ or both), with 403 patients $(62.9 \%)$ positive for both receptors, and $54(8.4 \%)$ negative for ER and PgR. Receptor status differed slightly between the axillary and no axillary treatment groups (chi-square $p=0.054 ; \mathrm{ER}-/ \mathrm{PgR}+$ and low-frequency $\mathrm{ER}-/ \mathrm{PgR}-$ fused).

Table 2 presents the distribution of first events and causes of death by treatment group, together with corresponding 15-year crude cumulative incidence estimates. Table 3 shows estimates of 15 -year crude cumulative incidence of main adverse events for each group in relation to postoperative radiotherapy and tumor variables. Note that these estimates are not covariate adjusted, so comparison between treatment groups is likely to be misleading

\begin{tabular}{lccc}
\hline & $\begin{array}{l}\text { No axillary dissection } \\
(N=499)\end{array}$ & $\begin{array}{l}\text { Axillary dissection } \\
(N=172)\end{array}$ & $\begin{array}{c}\text { Overall group } \\
(N=671)\end{array}$ \\
\hline Age (years), median (IQR) & $77(74-81)$ & $74(71-77)$ & $76(73-80)$ \\
Postoperative RT to breast & $145(29.1 \%)$ & $84(48.9 \%)$ & $229(34.1 \%)$ \\
Yes & $354(70.9 \%)$ & $88(51.1 \%)$ & $442(65.9 \%)$ \\
No & & & \\
Pathological tumor size & $296(59.3 \%)$ & $134(77.9 \%)$ & $430(64.1 \%)$ \\
pT1 & $164(32.9 \%)$ & $33(19.2 \%)$ & $197(29.4 \%)$ \\
pT2 & $3(0.6 \%)$ & $0(-)$ & $3(0.4 \%)$ \\
pT3 & $36(7.2 \%)$ & $5(2.9 \%)$ & $41(6.1 \%)$ \\
pT4b & & & $448(66.7 \%)$ \\
Histological type & $328(65.7 \%)$ & $120(69.8 \%)$ & $150(22.3 \%)$ \\
Infiltrating ductal carcinoma & $106(21.2 \%)$ & $44(25.6 \%)$ & $73(11.0 \%)$ \\
Infiltrating lobular carcinoma & $65(13.1 \%)$ & $8(4.6 \%)$ & \\
Other infiltrating carcinomas & & & $159(55-307)$ \\
Receptor status & & $100(24-261)$ & $68(1-316)$ \\
ER (fmol/mg), median (IQR) & $177(63-332)$ & $39(1-175)$ & $54(8.4 \%)$ \\
PgR (fmol/mg), median (IQR) & $83(1-363)$ & $19(11.9 \%)$ & $5(0.8 \%)$ \\
ER-/PgR- & $35(7.3 \%)$ & $179(27.9 \%)$ \\
ER-/PgR+ & $4(0.8 \%)$ & $81(32.1 \%)$ & $403(62.9 \%)$ \\
ER+/PgR- & $128(26.6 \%)$ & & \\
ER+/PgR+ & $315(65.4 \%)$ & & \\
\hline
\end{tabular}


TABLE 2 Unfavorable events in 671 elderly patients with operable breast cancer, by axillary treatment group
The figures in each cell are: number of patients and 15-year crude cumulative incidence estimates

\begin{tabular}{llll}
\hline Events & $\begin{array}{l}\text { No axillary dissection } \\
(N=499)\end{array}$ & $\begin{array}{l}\text { Axillary dissection } \\
(N=172)\end{array}$ & $\begin{array}{l}\text { Overall group } \\
(N=671)\end{array}$ \\
\hline First event & & & \\
Ipsilateral axillary disease & $30,5.8 \%$ & $0,0 \%$ & $30,4.3 \%$ \\
Distant metastasis & $49,9.9 \%$ & $20,11.6 \%$ & $69,10.3 \%$ \\
Ipsilateral breast tumor recurrence & $33,6.3 \%$ & $13,7.7 \%$ & $46,6.7 \%$ \\
Contralateral breast cancer & $9,1.8 \%$ & $4,2.3 \%$ & $13,1.9 \%$ \\
Second primary malignancy & $27,5.6 \%$ & $5,2.9 \%$ & $32,4.9 \%$ \\
Death for unrelated condition & $251,49.6 \%$ & $82,41.9 \%$ & $333,47.6 \%$ \\
Mortality & & & \\
Breast cancer & $71,14.0 \%$ & $23,13.6 \%$ & $94,13.9 \%$ \\
Other malignancy & $22,4.3 \%$ & $3,1.8 \%$ & $25,3.6 \%$ \\
Unrelated condition & $284,56.4 \%$ & $92,47.8 \%$ & $376,54.2 \%$ \\
\hline
\end{tabular}

TABLE 3 Breakdown of main adverse breast cancer events by postoperative radiotherapy (RT), tumor size, histological type, and receptor status for each axillary treatment group

\begin{tabular}{|c|c|c|c|c|c|}
\hline & \multicolumn{3}{|c|}{ No axillary dissection (499 patients) } & \multicolumn{2}{|c|}{ Axillary dissection (172 patients) } \\
\hline & $\begin{array}{l}\text { Ipsilateral axillary } \\
\text { disease }\end{array}$ & $\begin{array}{l}\text { Distant } \\
\text { metastasis }\end{array}$ & $\begin{array}{l}\text { Breast cancer } \\
\text { death }\end{array}$ & Distant metastasis & $\begin{array}{l}\text { Breast cancer } \\
\text { death }\end{array}$ \\
\hline \multicolumn{6}{|l|}{ Postoperative RT to breast } \\
\hline Yes & $\begin{array}{l}14,9.7 \% \\
(5.9-15.9 \%)\end{array}$ & $\begin{array}{l}18,12.4 \% \\
(8.1-19.2 \%)\end{array}$ & $\begin{array}{l}24,16.6 \% \\
(11.5-24.0 \%)\end{array}$ & $\begin{array}{l}12,14.3 \% \\
(8.4-24.2 \%)\end{array}$ & $\begin{array}{l}15,17.9 \% \\
(11.2-28.4 \%)\end{array}$ \\
\hline No & $\begin{array}{l}16,4.2 \% \\
(2.6-7.0 \%)\end{array}$ & $\begin{array}{l}31,8.8 \% \\
(6.3-12.3 \%)\end{array}$ & $\begin{array}{l}47,12.9 \% \\
(9.8-17.0 \%)\end{array}$ & $\begin{array}{l}8,9.1 \% \\
(4.7-17.7 \%)\end{array}$ & $\begin{array}{l}8,9.6 \% \\
(4.9-18.9 \%)\end{array}$ \\
\hline \multicolumn{6}{|l|}{ Pathological tumor size } \\
\hline pT1 & $\begin{array}{l}12,3.7 \% \\
(2.1-6.7 \%)\end{array}$ & $\begin{array}{l}20,6.8 \% \\
(4.4-10.4 \%)\end{array}$ & $\begin{array}{l}32,10.7 \% \\
(7.6-14.9 \%)\end{array}$ & $\begin{array}{l}12,9.0 \% \\
(5.2-15.4 \%)\end{array}$ & $\begin{array}{l}14,10.7 \% \\
(6.5-17.6 \%)\end{array}$ \\
\hline pT2-4b & $\begin{array}{l}18,8.9 \% \\
(5.7-13.8 \%)\end{array}$ & $\begin{array}{l}29,14.3 \% \\
(10.2-20.1 \%)\end{array}$ & $\begin{array}{l}39,18.8 \% \\
(14.1-25.1 \%)\end{array}$ & $\begin{array}{l}8,21.1 \% \\
(11.2-39.4 \%)\end{array}$ & $\begin{array}{l}9,23.7 \% \\
(13.2-42.4 \%)\end{array}$ \\
\hline \multicolumn{6}{|l|}{ Histological type } \\
\hline Infiltrating lobular carcinoma & $\begin{array}{l}4,3.8 \% \\
(1.4-9.9 \%)\end{array}$ & $\begin{array}{l}16,15.2 \% \\
(9.6-23.9 \%)\end{array}$ & $\begin{array}{l}22,20.9 \% \\
(14.3-30.4 \%)\end{array}$ & $\begin{array}{l}6,13.7 \% \\
(6.4-29.3 \%)\end{array}$ & $\begin{array}{l}7,16.0 \% \\
(8.0-31.9 \%)\end{array}$ \\
\hline Infiltrating ductal carcinoma & $\begin{array}{l}26,7.6 \% \\
(5.2-11.1 \%)\end{array}$ & $\begin{array}{l}29,8.9 \% \\
(6.3-12.6 \%)\end{array}$ & $\begin{array}{l}45,13.3 \% \\
(10.1-17.6 \%)\end{array}$ & $\begin{array}{l}14,11.7 \% \\
(7.1-19.1 \%)\end{array}$ & $\begin{array}{l}16,13.6 \% \\
(8.6-21.6 \%)\end{array}$ \\
\hline Other infiltrating carcinoma & $0,0.0 \%$ & $\begin{array}{l}4,6.2 \% \\
(2.4-16.1 \%)\end{array}$ & $\begin{array}{l}4,6.2 \% \\
(2.4-16.1 \%)\end{array}$ & $0,0.0 \%$ & $0,0.0 \%$ \\
\hline \multicolumn{6}{|l|}{ Receptor status ${ }^{\mathrm{a}}$} \\
\hline $\mathrm{ER}+/ \mathrm{PgR}+$ & $\begin{array}{l}16,4.8 \% \\
(2.9-7.8 \%)\end{array}$ & $\begin{array}{l}27,8.6 \% \\
(6.0-12.4 \%)\end{array}$ & $\begin{array}{l}39,12.3 \% \\
(9.1-16.6 \%)\end{array}$ & $\begin{array}{l}9,10.2 \% \\
(5.5-19.1 \%)\end{array}$ & $\begin{array}{l}12,14.1 \% \\
(8.3-24.1 \%)\end{array}$ \\
\hline $\mathrm{ER}+/ \mathrm{PgR}-$ & $\begin{array}{l}10,7.8 \% \\
(4.3-14.2 \%)\end{array}$ & $\begin{array}{l}14,11.0 \% \\
(6.7-18.0 \%)\end{array}$ & $\begin{array}{l}22,16.6 \% \\
(11.2-24.5 \%)\end{array}$ & $\begin{array}{l}7,13.8 \% \\
(6.9-27.7 \%)\end{array}$ & $\begin{array}{l}8,15.8 \% \\
(8.3-30.1 \%)\end{array}$ \\
\hline $\mathrm{ER}-{ }^{\mathrm{a}}$ & $\begin{array}{l}4,10.3 \% \\
(4.0-26.3 \%)\end{array}$ & $\begin{array}{l}7,17.9 \% \\
(9.1-35.5 \%)\end{array}$ & $\begin{array}{l}9,23.1 \% \\
(12.9-41.3 \%)\end{array}$ & $\begin{array}{l}3,15.0 \% \\
(5.1-43.9 \%)\end{array}$ & $\begin{array}{l}3,15.0 \% \\
(5.1-43.9 \%)\end{array}$ \\
\hline
\end{tabular}

The figures in each cell are: number of patients, 15-year crude cumulative incidence estimate, and corresponding 95\% confidence interval

${ }^{a}$ Only one ER-/PgR+ patient developed distant metastasis (14 months after surgery, death at 17 months), this category was therefore merged with the ER-/PgR - category as ER-. Events in the 30 patients with missing receptor status were: distant metastasis: 1 in axillary dissection group, 1 in no axillary dissection group; breast cancer death: 1 in axillary dissection group, 0 in no axillary dissection group 
due to the imbalances in baseline and prognostic characteristics.

Of the 172 patients who received axillary dissection, 58 $(33.7 \%)$ had pathologically involved axillary nodes, including $39(29.1 \%)$ among the 134 patients with pT1 disease. Of the 499 patients who did not receive axillary dissection, 30 developed ipsilateral axillary disease (12 in the pT1 group): most were rescued by delayed axillary dissection. Fifteen of these 30 patients subsequently developed distant relapse and died of breast disease, while 11/30 died of causes unrelated to breast cancer. Median time from primary surgery to axillary occurrence was 33 months (interquartile range 19-61 months); most (90\%) developed axillary disease in the 6 years after surgery.

The 15-year crude cumulative incidence of axillary occurrence in the no axillary dissection group was $5.8 \%$ [95\% confidence interval (CI): 4.1-8.3\%], being 3.7\% (CI: $2.1-6.7 \%$ ) in pT1 patients.

The 15-year crude cumulative incidence of breast cancer death was $14.0 \%$ (CI: $11.2-17.4 \%$ ) in the no axillary dissection group and $13.6 \%$ (CI: 9.2-19.9\%) in the axillary dissection group $(p=0.657)$. The corresponding figures were $10.7 \%$ (CI: 7.6-14.9\%) and 10.7\% (CI: 6.5-17.6\%), respectively, for pT1 patients ( $p=0.836)$, and $18.8 \%$ (CI: $14.1-25.1 \%$ ) and $23.7 \%$ (CI: $13.2-42.4 \%$ ), respectively, for pT2-4 patients $(p=0.708)$ (Fig. 1). Note that the estimates in Fig. 1, like those in Tables 2 and 3, are not adjusted for imbalances in baseline or prognostic characteristics, so comparison between treatment groups is likely to be misleading. According to the Fine and Gray model, breast cancer death did not differ significantly between the two treatment groups $(p=0.480)$, and the effect of axillary dissection on breast cancer mortality did not differ significantly in pT1 versus pT2-4b patients $(p=0.960$ for interaction of axillary dissection with pT) (data not shown).
Table 4 shows the results of the multivariable Cox models for investigating the prognostic effect of treatment on distant metastasis and breast cancer mortality with covariate adjustment. No significant axillary treatment effect was observed on the two investigated end points. As regards covariates, breast radiotherapy was not significantly associated with prognosis, whereas $\mathrm{pT}$ and histologic type were significantly associated with distant metastasis and breast cancer death, with higher risks associated with $>$ pT1 disease and lobular carcinoma. In addition, ER-negative disease was strongly associated with distant metastasis, with a hazard ratio (HR) over twice that for ER-positive/PgRpositive disease.

Of the 229 patients given radiotherapy, 8 experienced IBTR: 1 subsequently developed distant metastasis and died of breast disease, and 5 died of causes unrelated to breast cancer. Of the 442 patients not given radiotherapy, 38 had IBTR: 6 subsequently developed distant metastasis and died of breast disease, 3 died of other malignancy, and 15 of causes unrelated to cancer. Considering the 430 pT1 patients, $7 / 88(8.0 \%)$ of those given tamoxifen plus radiotherapy developed IBTR, and 28/342 (8.2\%) of those given tamoxifen only developed IBTR. All IBTRs were managed by conservative surgery, which was followed by radiotherapy in eight patients in the no radiotherapy group. The 15-year crude cumulative incidence IBTR was $3.5 \%$ (CI: $1.8-6.9 \%$ ) in patients given radiotherapy, and $8.4 \%$ (CI: $6.1-11.5 \%)$ in those not given radiotherapy $(p=$ 0.010). The corresponding figures for pT1 patients were 8.0\% (CI: 3.9-16.3\%) and 7.9\% (CI: 5.4-11.5\%), respectively $(p=0.845)$; in pT2-4 patients, crude cumulative incidences (CCIs) were $0.7 \%$ (CI: $0.1-5.2 \%$ ) and $10.0 \%$ (CI: 5.6-18.2\%), respectively ( $p<0.001$ ) (Fig. 2). The Fine and Gray multivariable analysis also showed that IBTR incidence differed significantly between the groups
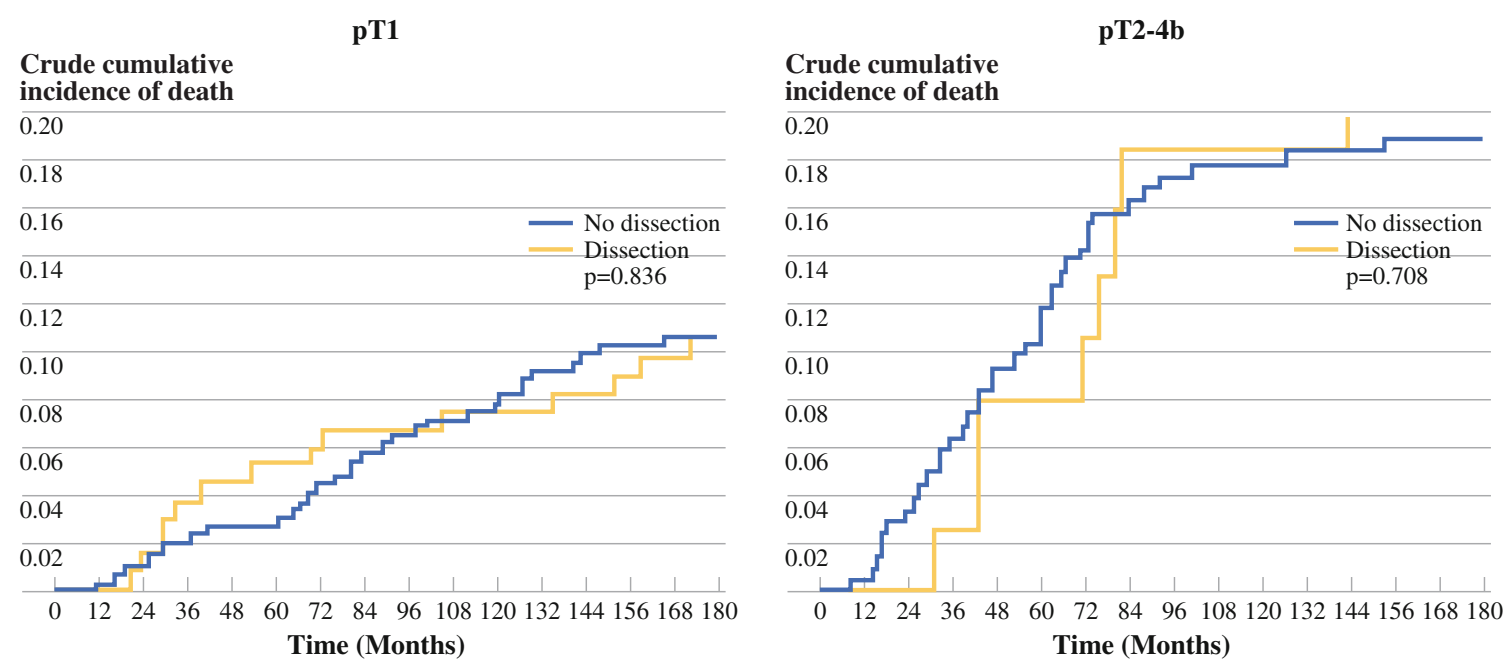

FIG. 1 Crude cumulative incidence curves of breast cancer death for patients given and not given axillary dissection. pT1 (left); pT2-4b (right) 
TABLE 4 Multivariable Cox analyses of influence of axillary treatment, postoperative radiotherapy (RT), tumor size, histology, and receptor status on distant metastasis and breast cancer death

\begin{tabular}{|c|c|c|c|c|c|c|}
\hline & \multicolumn{3}{|c|}{ Distant metastasis } & \multicolumn{3}{|c|}{ Breast cancer death } \\
\hline & HR & $95 \% \mathrm{CI}$ & $p$-Value & HR & $95 \% \mathrm{CI}$ & $p$-Value \\
\hline Axillary dissection & & & 0.831 & & & 0.372 \\
\hline Yes versus no & 0.9 & $(0.5-1.7)$ & & 0.8 & $(0.5-1.3)$ & \\
\hline Postoperative RT to breast & & & 0.382 & & & 0.376 \\
\hline Yes versus No & 0.7 & $(0.4-1.5)$ & & 0.8 & $(0.4-1.4)$ & \\
\hline Pathological tumor size & & & 0.001 & & & $<0.001$ \\
\hline pT2-pT4b versus pT1 & 3.2 & $(1.6-6.5)$ & & 2.8 & $(1.5-5.0)$ & \\
\hline Histologic type & & & 0.022 & & & 0.011 \\
\hline Lobular versus all other histotypes & 3.1 & $(1.1-9.0)$ & & 4.0 & $(1.4-11.4)$ & \\
\hline Ductal versus all other histotypes & 1.6 & $(0.6-4.5)$ & & 2.4 & $(0.9-6.6)$ & \\
\hline Receptor status & & & 0.107 & & & 0.251 \\
\hline $\mathrm{ER}+/ \mathrm{PgR}-$ versus $\mathrm{ER}+/ \mathrm{PgR}+$ & 1.2 & $(0.7-2.2)$ & & 1.3 & $(0.8-2.1)$ & \\
\hline $\mathrm{ER}-{ }^{\mathrm{a}}$ versus $\mathrm{ER}+/ \mathrm{PgR}+$ & 2.2 & $(1.1-4.4)$ & & 1.6 & $(0.9-3.0)$ & \\
\hline
\end{tabular}

$H R$ hazard ratio: risk increase (if $>1$ ) or decrease (if $<1$ ) associated with category versus reference category (assumed to have HR $=1$ ). $C I 95 \%$ HR confidence interval. $p$-Values from two-sided Wald test

${ }^{\text {a }}$ Due to low number of events the category ER-/PgR + was merged with ER-/PgR-
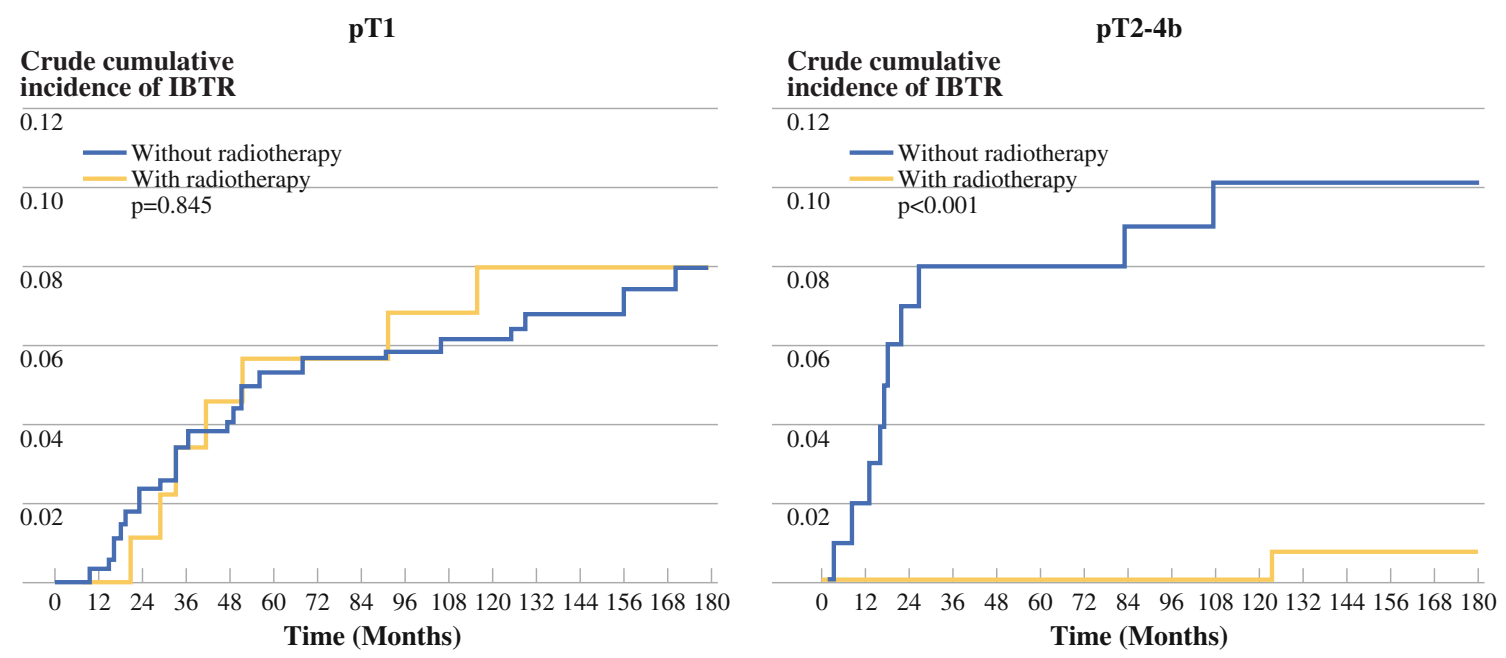

FIG. 2 Crude cumulative incidence curves of ipsilateral breast tumor recurrence (IBTR) for patients given and not given radiotherapy. pT1 (left); pT2-4b (right)

given and not given radiotherapy $(p=0.041)$ and that the effect of radiotherapy on IBTR differed significantly between the pT1 and pT2-4b groups $(p=0.014$ for axillary dissection $\times \mathrm{pT}$ interaction) (data not shown).

\section{DISCUSSION}

The most important finding of this study is that, after 15 years of follow-up in elderly patients with clinically node-negative early breast cancer treated by conservative surgery and tamoxifen, there was no significant advantage to axillary dissection in terms of breast cancer mortality.
Among the 172 patients who received prophylactic axillary dissection, $33.7 \%$ had positive axillary nodes on pathologic examination ( $29 \%$ of patients with pT1 disease), yet only 30/499 patients without axillary dissection (crude 15-year cumulative incidence 5.8\%) including 12/296 pT1 patients (crude 15-year cumulative incidence 3.7\%) developed overt axillary disease after 15 years of followup. This finding is consistent with the experience of others that the axillary recurrence rate is much lower than the rate of axillary involvement on pathological examination of resected axillary nodes. ${ }^{23-25}$ Consider, for example, the milestone NSABP B-04 trial which compared radical 
mastectomy with "simple" mastectomy in which muscles and axillary lymph nodes (unless axillary disease became evident during follow-up) were left in place. ${ }^{23}$ In this study $>70 \%$ of women were aged 50 years or above. After 25 years, no significant difference in disease-free, distant relapse-free or overall survival was observed between radical and simple mastectomy arms. Furthermore, only $18 \%$ subsequently developed overt ipsilateral axillary disease in the simple mastectomy arm, compared with the $40 \%$ expected based on the proportion with a positive axilla after prophylactic axillary dissection.

The more recent Veronesi trial on patients aged over 45 years with breast cancer up to $1.2 \mathrm{~cm}$ had similar findings. ${ }^{24}$ These patients received breast-conserving surgery without axillary dissection, and were randomized to axillary radiotherapy or no axillary treatment. Distant metastasis-free and overall survival did not differ between the two arms, and the rate of axillary relapse in the no axillary treatment arm was only $1.5 \%$ after 5 years.

Another recently published randomized trial on women $\geq 60$ years of age with breast cancer and a clinically nodenegative axilla compared surgery with axillary dissection and surgery without axillary dissection followed by tamoxifen for 5 years. ${ }^{25}$ This study found that presence of axillary lymph node involvement did not affect diseasefree or overall survival after median follow-up of 6.6 years.

Our own randomized trial, published in 2005 on patients $\geq 65$ years of age with T1N0 breast cancer randomly assigned to breast-conserving surgery with or without axillary dissection followed by tamoxifen for 5 years, also showed no advantage in terms of breast cancer mortality or overall survival for axillary dissection after 5 years of follow-up. ${ }^{14}$ Only $1.2 \%$ of patients in the no axillary dissection arm developed overt axillary involvement.

Two major points emerge from all these studies: rates of overt axillary metastases in those receiving no axillary treatment are much lower than expected; and overall survival and breast cancer mortality do not differ between the axillary treatment and no axillary treatment arms. Axillary dissection may be associated with more accurate staging and improved regional control, but it does not affect breast cancer mortality or overall survival-most conspicuously in older women-supporting the hypothesis that the biologic behavior of the primary mainly determines whether metastatic spread occurs and hence whether the patient will die of her disease. ${ }^{26}$ The recent hypothesis that only cancer stem cells give rise to metastases may be of relevance here: these cells are supposed to be slow growing and form only a small proportion of the total population of cancer cells; they may require many years to develop into overt disease recurrence. $^{27,28}$ Little is known, however, regarding the characteristics of breast cancer stem cells.
In the present study over $90 \%$ of tumors were ER+, as is normally the case in elderly women. Long-term tamoxifen treatment is known to keep cancer at bay for many year, if not indefinitely, and this may have been an important reason why the rate of overt axillary disease was low in our series. ${ }^{29,30}$

As expected, the multivariable Cox analysis found that large tumor size was a major predictor of distant metastases and breast cancer death in our series, with HRs of 2.6 and 2.3 , respectively, for $>\mathrm{pT} 1$ compared with $\mathrm{pT} 1$ tumors (Table 4). Somewhat unexpectedly the Cox analysis also showed that invasive lobular histology was a very strong predictor of distant metastasis and breast cancer death compared with other histologies (Table 4). This finding is in contrast to a 2004 study which found identical overall and disease-free survival in lobular and ductal carcinoma. ${ }^{31} \mathrm{We}$ also found that ipsilateral axillary disease was much more frequent in patients with ductal histotype (Table 3). Furthermore ER-negative tumors were strongly associated with development of distant metastasis. It also appears from Table 3 that, for both groups, postoperative radiotherapy was associated with greater 15-year crude cumulative incidence of adverse events (even though confidence intervals were wide and overlapping). This is because the groups were not stratified (in this table) for tumor size. Larger tumor size in this nonrandomized study will have increased the likelihood of both adverse events and also increased the likelihood of receiving radiotherapy. The multivariable analysis (Table 4) showed radiotherapy to have no influence on outcome in the two groups. However, while 15-year crude cumulative incidence of IBTR in elderly patients with pT1 breast cancer did not differ significantly between the radiotherapy and no radiotherapy groups (and was fairly low at about $8 \%$ ), the incidence of IBTR was much higher $(p<0.001$, Fig. 2) in patients with larger cancers who did not receive radiotherapy. The role of radiotherapy in conservatively treated patients aged $\geq 70$ years with T1N0 ER+ breast cancer was investigated in a recent trial. ${ }^{32}$ The patients were randomly assigned to postoperative radiotherapy versus no postoperative radiotherapy to the breast, followed by adjuvant tamoxifen. After 5 years, rates of local relapse were $1 \%$ in the radiotherapy group and $4 \%$ in the no radiotherapy group, with no difference in overall survival or breast cancer mortality. In the Veronesi trial that investigated the importance of breast radiotherapy in patients with breast cancer up to $2.5 \mathrm{~cm}$ receiving conservative surgery, the difference in local relapse rate between the radiotherapy and no radiotherapy arms decreased with advancing age, so that in women aged $\geq 55$ years the difference was minimal, and in women aged $\geq 65$ years the difference was no longer present. $^{33}$

These data suggest that, in elderly patients with early breast cancer receiving adequate conservative surgery and long-term tamoxifen, radiotherapy may be safely omitted. 
Nevertheless our data strongly suggest that radiotherapy is essential in older patients with large tumors.

To conclude, data from the present nonrandomized study and several other studies including randomized trials strongly suggest that elderly patients with early breast cancer and clinically negative axillary nodes do not benefit from axillary dissection. ${ }^{14,23-25}$ Sentinel node biopsy should also be omitted, as axillary dissection did not impact breast cancer mortality in our study, and the pathological information provided by resected axillary nodes is unlikely to influence adjuvant therapy options, particularly since hormonal therapy is standard for all patients with receptor-positive disease.

We also found that elderly patients with receptor-negative disease had significantly greater rates of distant metastases and breast cancer death than those with receptor-positive tumors, and these patients present a treatment dilemma since hormonal therapy is not indicated. Thus treatment for early-stage breast cancer in elderly patients should be reevaluated; in particular, axillary node dissection should be restricted to patients with clinically involved nodes. We note, finally, that it would be preferable to confirm our findings with a randomized trial, notwithstanding the difficulties in conducting randomized trials in elderly patients, since undetected differences between the groups could have influenced the result.

ACKNOWLEDGMENT This paper is dedicated to Professor G. De Palo of the Milan National Cancer Institute and Foundation, who died recently. The authors thank Don Ward for help with the English.

OPEN ACCESS This article is distributed under the terms of the Creative Commons Attribution Noncommercial License which permits any noncommercial use, distribution, and reproduction in any medium, provided the original author(s) and source are credited.

\section{REFERENCES}

1. Ferlay J, Bray F, Pisani P, et al. Cancer incidence, mortality and prevalence worldwide. IARC Cancer Base No. 5, version 2.0. Lyon: IARC Press GLOBOCAN; 2004.

2. Parkin DM, Bray F, Ferlay J, et al. Global cancer statistics, 2002. CA Cancer J Clin. 2005;55:74-108.

3. Gazet JC, Ford HT, Coombes RC, et al. Prospective randomized trial of tamoxifen vs surgery in elderly patients with breast cancer. Eur J Surg Oncol. 1994;20:207-14.

4. Fennessy M, Bates T, Mac Rae K, et al. Late follow-up of a randomized trial of surgery plus tamoxifen versus tamoxifen alone in women aged over 70 years with operable breast cancer. Br J Surg. 2004;91:699-704.

5. Mustacchi G, Ceccherini R, Milani S, et al. Tamoxifen alone versus adjuvant tamoxifen for operable breast cancer of the elderly: long-term results of the phase III randomized controlled multicenter GRETA trial. Ann Oncol. 2003;14:414-20.

6. Fentiman IS, Christiaens MR, Paridaens R, et al. Treatment of operable breast cancer in the elderly: a randomized clinical trial
EORTC 10851 comparing tamoxifen alone with modified radical mastectomy. Eur J Cancer. 2003;39:309-16.

7. Giuliano AE, Kirgan DM, Guenther JM, et al. Lymphatic mapping and sentinel lymphadenectomy for breast cancer. Ann Surg. 1994;220:391-401.

8. Veronesi U, Paganelli G, Galimberti V, et al. Sentinel node biopsy can avoid axillary dissection in breast cancer patients with clinically negative lymph-nodes. Lancet.1997;349:1864-7.

9. Cox C, White L, Allred N, et al. Survival outcomes in nodenegative breast cancer patients evaluated with complete axillary node dissection versus sentinel lymph node biopsy. Ann Surg Oncol. 2006;13:708-11.

10. Lyman GH, Giuliano AE, Somerfield MR, et al. American Society of Clinical Oncology guideline recommendations for sentinel lymph node biopsy in early-stage breast cancer. J Clin Oncol. 2005;23:7703-20.

11. Gervasoni JE, Sbayi S, Cady B. Role of lymphadenectomy in surgical treatment of solid tumors: an update on the clinical data. Ann Surg Oncol. 2007;14:2443-62.

12. Kenny FS, Robertson JFR, Ellis IO, et al. Long-term follow-up of elderly patients randomized to primary tamoxifen or wedge mastectomy as initial therapy for operable breast cancer. Breast.1998; 7:335-9.

13. Hind D, Wyld L, Beverley CB, et al. Surgery versus primary endocrine therapy for operable primary breast cancer in elderly women (70 years plus). Cochrane Database Syst Rev. 2006;1: CD004272.

14. Martelli G, Boracchi P, De Palo M, et al. A randomized trial comparing axillary dissection to no axillary dissection in older patients with T1N0 breast cancer: results after 5 years of followup. Ann Surg. 2005;242:1-6.

15. Martelli G, Miceli R, De Palo G, et al. Is axillary lymph node dissection necessary in elderly patients with breast carcinoma who have a clinically uninvolved axilla? Cancer. 2003;97: 1156-63.

16. Ronchi E, Granata G, Brivio M, et al. A double-labeling assay for simultaneous estimation and characterization of estrogen and progesterone receptors using radioiodinated estradiol and tritiated Org 2058. Tumori. 1986;72:251-7.

17. Marubini E, Valsecchi MG. Analysing survival data for clinical trials and observational studies. Chichester, UK: Wiley; 1995.

18. Gray RJ. A class of k-sample tests for comparing the cumulative incidence of a competing risk. Ann Stat. 1988;16:1141-54.

19. D'Agostino RB. Tutorial in biostatistics. Propensity score methods for bias reduction in the comparison of a treatment to a nonrandomized control group. Stat Med. 1998;17:2265-81.

20. Fine JP, Gray RJ. A proportional hazards model for the subdistribution of a competing risk. J Am Stat Assoc. 1999;94:496-509.

21. SAS Institute Inc. SAS procedures guide, version 6. 3rd ed. Cary, NC: SAS Institute Inc.; 1990.

22. R Development Core Team: R: a language and environment for statistical computing. Vienna, Austria: R Foundation for Statistical Computing. ISBN 3-900051-07-0, http://www.R-project.org (2007). Accessed 10 Nov 2009.

23. Fisher B, Jeong JH, Anderson S, et al. Twenty-five-year followup of a randomized trial comparing radical mastectomy, total mastectomy and total mastectomy followed by irradiation. $N$ Engl J Med. 2002;347:567-75.

24. Veronesi U, Orecchia R, Zurrida S, et al. Avoiding axillary dissection in breast cancer surgery: a randomized trial to assess the role of axillary radiotherapy. Ann Oncol. 2005;16:383-8.

25. Rudenstam CM, Zahrieh D, Forbes JE, et al. Randomized trial comparing axillary clearance versus no axillary clearance in older patients with breast cancer: first results of International Breast Cancer Study Group trial 10-93. J Clin Oncol. 2006;24:337-44. 
26. Sanghani M, Balk EM, Cady B. Impact of axillary lymph node dissection on breast cancer outcome in clinically node negative patients. Cancer. 2009;115:1613-20.

27. Clarke MF, Fuller M. Stem cells and cancer: two faces of eve. Cell. 2006;124:1111-5.

28. Zhang M, Rosen JM. Stem cells in the etiology and treatment of cancer. Curr Opin Genet Dev. 2006;16:60-4.

29. Fowble B, Fein DA, Hanlon AL, et al. The impact of tamoxifen on breast recurrence, cosmesis, complications, and survival in estrogen receptor-positive early-stage breast cancer. Int J Radiat Oncol Biol Phys. 1996;35:669-77.

30. Fisher B, Constantino J, Redmond C, et al. A randomized clinical trial evaluating tamoxifen in the treatment of patients with node- negative breast cancer who have estrogen receptor-positive tumors. N Engl J Med. 1989;320:479-84.

31. Arpino G, Bardou VJ, Clark GM et al. Infiltrating lobular carcinoma of the breast : tumor characteristics and clinical outcome. Breast Cancer Res. 2004;6:149-56.

32. Hughes KS, Schnaper LA, Berry D, et al. Lumpectomy plus tamoxifen with or without irradiation in women 70 years of age or older with early breast cancer. N Engl J Med. 2004;351:971-7.

33. Veronesi U, Marubini E, Mariani L, et al. Radiotherapy after breast conserving surgery in small breast carcinoma: long term results of a randomized trial. Ann Oncol. 2001;12:997-1003. 